\title{
3 The technoethics of contemporary intelligence practice
}

\author{
A framework for analysis
}

David Omand and Mark Phythian

\section{Introduction}

Intelligence agencies have a history of rapid exploitation of the latest scientific and technological advances, from the electric telegraph to radio transmissions and satellite observation. As with warfare, the history of intelligence can be told in terms of the relative advantage bestowed by a series of technological innovations (McNeill 1983; Warner 2014). This historically close relationship between intelligence and technology marks out intelligence as a sphere of activity where issues of "technoethics"1 - of the way in which technological developments impact on the nature of ethical frameworks and judgements and the inter-relationship between the two - are prevalent. The digitization of information of all kinds is the latest field of technological innovation to generate ethical dilemmas for intelligence practice. Some of the ethical issues raised by intelligence use of digital information are simply modern forms of age-old dilemmas now being shaped by new technologies, such as judging when invasions of privacy are justified. Others arise because of the development of digital technology itself, such as the application of Artificial Intelligence (AI) algorithms to enable facial recognition or the placing of malware on a target computer network. Taken together, these questions about the ethics of using digital technology for intelligence purposes call for a specific examination of "technoethics", drawing where relevant on the ethical guidance available from other disciplines such as for the safe use of advanced medical devices and artificial intelligence algorithms.

In this chapter our focus is on the ethical challenges posed by the still rapidly developing sphere of digital intelligence. Indeed, so pervasive are the challenges it poses that, as we emphasize in this chapter, it is increasingly misleading to approach it as a discrete sphere of activity. It proceeds as follows: we begin by recalling the fundamental origin of the ethical concerns over intelligence activity and set out the ethical principles that we have derived in our previous work from the Just War tradition (Omand and Phythian 2018). We then discuss the contemporary landscape of intelligence technoethics, followed by a proposed framework for thinking about the technoethics of intelligence, using jus in intelligentia concepts and focusing on the importance of norm development, and the requirements for effective norm development, in this area.

DOI: $10.4324 / 9781003164197-5$ 


\section{An ethical framework for secret intelligence}

States invest in intelligence and data collection to provide a sound basis for their decisions, especially regarding the security, safety and health of their citizens. Much of the information needed to protect the public can come from open sources. But there are threats emanating from beyond and within national borders from malign actors (hostile states, terrorists, cyber criminals and their ilk) who are determined to conceal their capabilities and intentions and to expose them requires secret intelligence (Omand and Phythian 2018, chap. 1). The means by which states, via investment in intrusive information gathering, seek to protect against such threats and protect their interests more widely, including from natural hazards, can create tensions in relation to liberal principles. Consequently, there is a strong case for accepting that intrusive data gathering and secret intelligence, if judged necessary, requires a code of ethics different from that we would want to regulate everyday conduct in a liberal democracy.

This is because, fundamentally, espionage is about acquiring secrets held by another ("stealing secrets") in conditions where the person with the secret may go to extreme and often violent means to prevent their secrets being compromised. Having to overcome the determined will of the person with the secret takes us into behaviours that could never satisfy the kind of ethical threshold mandated by Kantian ethics. Using people as means to an end, subverting them from their duty in order that they spy on your behalf, intruding on personal privacy and employing deceptive practices are the essence of intelligence tradecraft. Only preventing serious harm to others can morally justify such methods. However, there are sufficient serious threats facing the democracies to provide the justification.

Yet, the exercise of secret intelligence activity in liberal democracies cannot be without ethical and legal constraints. Rather like the technologist in Mario Bunge's mid-1970s outline of a "technoethics", the intelligence professional in the liberal state is caught between conflicting demands that cannot necessarily be pursued independently of each other but need to be balanced (Bunge 1977, 98). ${ }^{2}$ The professional cannot slough off ethical responsibility onto the policy maker just as the technologist cannot simply hide behind the user of the technology. A case can be made for seeing basic science as value-neutral but its technological application is a human-directed activity and the developers of technology need to be aware of how their innovations may be used for ill as well as good. But how should liberal democracies arrive at ethical guidelines that govern intelligence practice? How should they seek to arrive at this balance? One solution to this knotty problem is to look to draw parallels with the development over the centuries, under the Just War tradition, of ways to constrain the conditions under which states may go to war (jus ad bellum) and the conduct of their armed forces when so engaged (jus in bello). If the application of the extreme violence of armed conflict can be constrained by an ethically based code then on the legal principle of omne majus continent in se minus it should be possible to envisage ethical limitations on secret intelligence activity - a jus ad intelligentiam informed by thinking in terms of jus ad bellum and a jus in intelligentia based on thinking around principles of jus in bello. This 
is not to say that thinking in terms of parallels can offer neat or simple solutions to dilemmas concerning intelligence practice in liberal democracies - any assumption that it could offer anything approaching a tick-box solution would be counterproductive - but it does offer the best available set of concepts for thinking about the ethics of intelligence, one that can be universally applied as states anticipate and address the challenges they will inevitably face. On this basis, in our earlier work we derived such a set of jus in intelligentia concepts that we believe can be of use in reaching ethical judgements about the conduct of intelligence activity, including the use of advanced technologies, by the security and intelligence authorities of liberal democratic states (Omand and Phythian 2018, chap. 3):

- right intention - acting with integrity and having no ulterior motive or other agenda behind the authorization of intelligence activity or in analysis, assessment and the presentation of intelligence judgements to decision makers

- proportionality - ensuring that the ethical risks of operations are in line with the harm that the operations are intended to prevent

- right authority - establishing the level appropriate to the ethical risks that may be run and that will then allow for accountability for decisions and oversight of the process

- reasonable prospect of success - having adequate justification for the expectation that conducting individual operations will be likely to deliver results of value, given the ethical risks associated with them, including risks to agents and their families

- discrimination - having the ability to assess and manage the risk of unintended (collateral) harm, such as privacy intrusion into the lives of those who are not the intended targets of intelligence gathering

- necessity - there being no other reasonable way to achieve the authorized mission at lesser ethical risk

Later in this chapter we illustrate the use of these principles as applied to ethical issues arising from the use of digital technology by intelligence agencies.

\section{The technoethics of intelligence: the impact of digitization and the internet}

Digitization is the conversion of any form of information into numerical form (usually, but not necessarily, expressed in binary code). Speech and sound, visual images (still and moving), geolocation, text, radar and other electromagnetic radiation, DNA, patterns and logical structures text, and much else by way of information available in analogue form can all be accurately rendered as strings of numbers. Having information held as digital data has great economic and practical advantages:

- Large volumes of numerical data can be moved cheaply in bulk over any distance and terrain (and across oceans), for example by fibre-optic cables, microwave links and satellite links. 
- Public key encryption can provide strong end-to-end security for data in motion without effort by the user (thus enabling digital commerce and financial transactions).

- The internet provides a (permissionless) ability to link computer networks together using open protocols, and thus provides global connectivity. The World Wide Web internet carries provide easy access to data in user-friendly formats, one example social media.

- Personal smart mobile devices are now cheap and very powerful, and 5G networks will allow high bandwidth, low latency and connectivity even on the move.

- Digital data can be stored at reasonable cost, with data science developed to provide powerful ways of searching and data mining very large data sets (without needing to structure data with fields defined in advance).

- Machine learning systems and advanced AI algorithms can be used to carry out classification tasks, increasingly more accurately than even trained humans, for example in detecting malign tumours, operating passport facial recognition systems at borders or spotting anomalous behaviour in a computer network.

- The Internet of Things enables everyday household and personal devices (including sports and personal health technology) to be internet connected. Digital cities increasingly have internet-connected infrastructure for congestion charging, traffic light control, water and energy metering and telecoms systems.

These developments have provided exploitable characteristics of interest to national security and intelligence agencies. Given the nature of the international system these exploitable characteristics constitute both opportunities and vulnerabilities. Alex Younger drew attention to these in a rare speech by a serving Chief of the Secret Intelligence Service (SIS, or MI6), delivered at the University of St. Andrews in December 2018, when he set out how we are now, "in the early stages of a fourth industrial revolution that will further blur the lines between the physical, the digital and biological realms" and that he had seen the

damage new technologies can do in the hands of a skilled opponent unrestrained by any notion of law or morality, as well as the potentially existential challenge the data age poses to the traditional operating methods of a secret intelligence agency.

This meant, for Younger, that "We and our allies face a battle to make sure technology works to our advantage, not to that of our opponents" (Younger 2018). We can identify eight core dimensions of the fundamental problem this gives rise to:

1 access to bulk data - defined as mining a large volume of data containing information almost all of which is known not to be relevant to an intelligence requirement or investigation. Unlike with the rented telephone lines of past 
eras the internet works on packet switched networks where the individual packets that make up any form of communication may be directed automatically on different global paths dependent on cost at that instant. Access to bulk traffic nevertheless provides an opportunity to discover who was calling whom, when, where and how (communications data), or to try to gain access to specific communications of interest (communications content).

2 network exploitation - the lengthy and complex code used in computer operating systems and applications inevitably contains mistakes and weaknesses that can be discovered and exploited to gain access to networks, machines and communications (including so-called zero-day exploits).

3 attribution - anonymity is hard wired into the internet protocols, making it difficult for security services and law enforcement to definitively attribute harmful material on the internet, including disinformation, racial and personal abuse and criminal attacks, sabotage and foreign subversion via information operations.

4 data sabotage - the global nature of the internet allows remote attacks for intelligence gathering and for sabotage, including contaminating and denying stored digital data. Software and some hardware components can if accessed be corrupted covertly or denied to users.

5 criminal ransomware - ransomware malware attacks demand payment to criminals to restore access. Constraints of space and time no longer hinder the scale of such hostile activity - attacks can arrive against multiple targets in many countries at near the speed of light from jurisdictions that will not cooperate with law enforcement investigations.

6 critical infrastructure vulnerability - the digital control systems and software that operate almost all critical national infrastructure such as power generation, water supply, manufacturing and logistics, as well as finance, are all vulnerable to cyberattack.

7 the business model of the internet involves capturing the personal data and internet browsing history of individuals and exploiting this data for marketing purposes - so-called surveillance capitalism (Zuboff 2019). Such "ad tech" involves real-time auctions of space for advertising according to the desired characteristics of the intended viewer, including from targeting their personal data and internet browsing history. Ad tech similarly allows the targeting of personalized political marketing as well as of commercial products and services.

8 the spread of social media and its use as the main source of information for younger generations creates vulnerabilities for democracies in the face of intimidatory posts, fake news, manipulative marketing and weaponized information.

Hence, while digitization brings significant benefits to society it also facilitates threats from hostile intelligence agencies and sub-state criminal entities. This no more than reflects the contemporary reality that the same digital tools are available to all advanced states, and increasingly to non-state groups. These tools also 
provide equivalent opportunities for the security and intelligence agencies of liberal democracies to pose the same types of threat as they face and experience from other states in the international system. This is the landscape of the modern digital battlefield where jus in intelligentia rules are needed.

One characteristic of this landscape is its complexity which has washed away notions of binary divides that traditionally acted as organizing principles in thinking about security challenges. As Younger explained in December 2018:

This complexity has eroded the boundaries we have traditionally relied upon for our security: the boundaries between virtual and real, the domestic and the international, between states and non-state actors and between war and peace. The result is a world of far greater ambiguity.

(Younger 2018)

Neither are notions of security simply about state behaviour and the actions of non-state actors. Yet even when they are not, this complexity remains a defining characteristic, mandating, potentially, multiple roles for intelligence agencies which serve to emphasize the technoethical dimension of contemporary intelligence work.

The example of the COVID-19 pandemic illustrates this well. Modern digital surveillance, including the use of apps on mobile devices and monitoring of digital personal information, has provided health authorities in nations such as South Korea, Singapore and China the public health benefit of powerful tools for assisting in testing and tracking programmes limiting the spread of the virus. For a virus in a globalized world national borders are no longer significant barriers but the unit of account for political decision-making is still the nation-state.

This takes us to the health-security interface. As a number of observers have noted, there are parallels that can be drawn between intelligence analysis and medical diagnosis, giving rise to a space in which mutual learning can take place. ${ }^{3}$ As we discuss later, we can usefully extend this thinking to cover parallels in intelligence and medical ethics. However, COVID-19 also illustrates three further things around this interface. First, it illustrates well how notions of national security intelligence are in the process of being adapted and how the shift from the Secret State of the Cold War era to the Protecting State of the twenty-first century continues apace (Omand 2010, chap. 1). ${ }^{4}$ National security is increasingly recognized as having a public safety and health dimension, and the COVID19 pandemic has acted as a catalyst in advancing this recognition. At the same time, the COVID-19 crisis contains a more traditional challenge for western intelligence agencies - preventing others from stealing COVID-19 vaccine secrets (Philp 2020).

Second, the case of COVID-19 illustrates the nature of a modern "infodemic" with the internet and social media rapidly spreading disinformation about (worthless) treatments for the disease or for preventing infection, including the alleged healing powers of hairdryers and malaria medicines (Jankowicz and Otis 2020). COVID-19 also illustrates the deliberate use of social media by foreign states to 
spread conspiracy stories, in this case about the origin of the outbreak with both Russia and China in different ways pushing the story that a US military laboratory was the source. This phenomenon in turn poses questions about how targeted states should respond and what role, if any, intelligence agencies should have in this. As Josep Borrell, the High Commissioner of the European Commission, warned in June 2020:

Disinformation in times of the coronavirus can kill. We have a duty to protect our citizens by making them aware of false information, and expose the actors responsible for engaging in such practices. In today's technologydriven world, where warriors wield keyboards rather than swords and targeted influence operations and disinformation campaigns are a recognised weapon of state and non-state actors, the European Union is increasing its activities and capacities in this fight.

(European Commission 2020)

The ease with which digital disinformation can be deliberately constructed and targeted at specific groups is itself a direct threat to democracy when coupled to the increasing susceptibility of the public to digital manipulation. We have evidence, not least from the 2016 US Presidential election, of a readiness uncritically to recirculate realistic fakes, hoaxes and lurid exaggerations. In future we can expect to see more hyper-partisan populist views and conspiracy laden arguments on social media. Accompanying those trends will be a further decline in the intellectual standards of political argument, a coarsening of debate, a failure to defend scientific reasoning and an unwillingness to apply evidence properly to policymaking. Voter cynicism about the motives of politicians and resulting low election turnout are likely consequences (Omand 2020, chap. 11).

Finally, the COVID-19 pandemic also illustrates well how the technoethics of intelligence can trigger liberal democratic concerns over privacy in a domestic context. The National Cyber Security Centre, a part of the Government Communications Headquarters (GCHQ), was involved in the design of the government's planned contact tracing app, assisting NHSX, the technology and digital branch of the National Health Service. GCHQ has long had the responsibility for being the technical authority for the cryptographic security of sensitive national systems. However, while United Kingdom (UK) citizens were keen to accept governmental intervention in the form of pandemic Keynesianism in the economic sphere, some were less enthusiastic about the prospect of comprehensive government health monitoring in the form of a centralized model track and trace app. ${ }^{6}$ Hence, alongside the more pronounced concerns over the potential for the Chinese state to use the COVID-19 crisis as an opportunity to increase surveillance of its citizens, some privacy and security experts in the UK warned of the risk of hackers accessing personal data and of domestic slippery slopes and "Orwellian overtones" (Naughton 2020a). Concerns about the possible consequences of acquiescing in the creation of the "Coronopticon" co-exist alongside recognition of the obvious health benefits of interventions aimed at tracking (The Economist 2020). 
Such apps to be effective require use by a significant proportion of the public and that level of uptake depends crucially on trust that the authorities will safeguard personal data from hackers and only use the information to be accessed for the stated purpose (Hart et al. 2020).

\section{Meeting the challenges posed by the contemporary technoethics of intelligence}

Hence, the COVID-19 global emergency illustrates well the importance of state agencies operating in the digital sphere in order to protect intellectual property, prevent the unchallenged spread of misinformation and collect data on individual exposure to the virus that can allow for interventions intended to limit the spread of the disease. At the same time, it also illustrates how such interventions can give rise to privacy concerns. In thinking about how to balance these competing demands, principles adopted from Just War thinking can make an important contribution. After all, as Danielle Allen and her colleagues note, there are core parallels in the war and pandemic contexts for liberal democratic states:

In both situations, the goal is to defeat the adversary with minimal loss of life and minimal damage to the material supports of a healthy economy and society, without perpetrating injustice, and while also pursuing defeat of the adversary in a way that both lays a foundation for a transition back to a peace-time setting and preserves the polity's political institutions to a maximal extent throughout the crisis and with a view to perpetual sustainability. That is, the goal is not to defeat the adversary at any cost but to preserve one's society, including preserving it as the kind of society it is.

(Allen et al. 2020) ${ }^{7}$

The Just War-derived ethical concepts listed earlier can be used to help unpack the ethical challenges that arise (Omand and Phythian 2018, 79-83). ${ }^{8}$

\section{Right intention and integrity of motive}

Right intention and integrity of motive on the part of those initiating, authorizing and conducting operations. The principle of right intention does not rule out deception in the course of an intelligence operation, such as inserting into the digital code of malware clues that attempt to encourage a false-flag attribution to a third country. But there must be no deception of government or Parliamentary oversight, or hidden domestic political or personal agendas lying behind the authorization or the conduct of digital intelligence activity. In the only recorded UK instance of such conduct, a GCHQ employee who deliberately undertook a number of unauthorized digital searches on an individual was sacked on the spot (Norton-Taylor 2015). In line with this approach, the analysis, assessment and presentation of the case for authorization to the relevant executive and judicial decision makers must be scrupulously honest, for example about estimates 
of collateral intrusion or other unintended consequences. Public confidence in government's use of digital intelligence technology depends upon upholding this principle.

We can see in this a key difference between intelligence ethics and medical ethics. A key demand of medical ethics is transparency over the risks of any medical procedure linked to the giving of specific informed consent by the patient. This is not possible in the world of secret intelligence - for example, for the individual citizen whose personal data is to be accessed in the course of intrusive surveillance - without vitiating the intelligence gathering operation. Consent has therefore to be given not individually but collectively though Parliamentary regulation following as transparent a debate as possible given legitimate security concerns and with the added protection of informed scrutiny via external oversight.

Similarly, it is an accepted principle in medical research that drug and treatment trials require independent ethical approval and the informed consent of those taking part, and the same is true for academic research involving individual participants. The intelligence agencies also need to research and trial their innovations and new procedures for accessing and mining data (on which they depend to keep one step ahead of their targets), but they have to conduct this activity in secret. Proposals for major trials should nevertheless be subject to independent scrutiny by the senior judge acting as the Investigatory Powers Commissioner to ensure that the proportionality and necessity tests are satisfied, thus protecting the interests of the individual data owners whose information is to be accessed. The Edward Snowden leaks exposed a 2002 case in which GCHQ conducted a major trial (in the end unsuccessful) of a new system for scraping still images from bulk data (Optic Nerve) (Ackerman and Ball 2014). The subsequent controversy added to the case for updating legislation to take account of digital technology and for strengthening oversight arrangements, now in place via the UK's 2016 Investigatory Powers Act.

\section{Proportionality of means in relation to the ends to be secured}

Assessing proportionality has to be done by carrying out a balancing exercise in which the risks of intelligence operations - the potential for unintended harm to others - are set against the anticipated harms to the public that they are designed to avert; for example, the access to bulk data containing the communications of those not the subject of investigation set against the threat to life and property averted by uncovering a terrorist attack plot. Such proportionality judgements involve weighing up many kinds of uncertainty, for which the UK Courts have been willing to allow "a margin of appreciation" for the decisions taken by the security and intelligence agencies (Anderson 2014, 76).

There is also an element of counter-factual thinking involved in such balancing when it comes to authorization of an operation since not conducting the operation also involves potential ethical risk. As John Stuart Mill pointed out in the midnineteenth century: "A person may cause evil to others not only by his actions but by his inaction, and in either case he is justly accountable to them for the 
injury" (Mill 1869, chap. 1). This principle is well established in medical ethics, for example in the balancing act that a clinical team may have to make in intervening in medical emergencies in childbirth or following major accidents. Another example of proportionality judgement is in the licensing of new drugs and therapies where the expected benefits to a large number of sufferers from a disease have to be balanced against the risks of adverse side effects for a small number of patients and how far that can be mitigated by training of clinicians and warning leaflets with prescriptions.

\section{Right authority for intelligence activity}

"Right" in the secret intelligence context means both that the go-ahead is given by someone who has the authority to give it under rights-compliant law and that the decision is taken at a senior enough level appropriate to the ethical risks that may be run (an important consideration in ensuring that the activity is not "arbitrary" in the words of the UN Universal Human Rights Declaration). In general, the more sensitive the operation the more senior should be the authorizer. Under the UK Investigatory Powers Act 2016, for example, warrants to allow intelligence access by using digital bulk data must be signed by the Secretary of State and then judicially reviewed and counter-signed by a senior judge acting as a Commissioner under the terms of the Act. Authority to access communications data (considered less inherently sensitive than the content of communications) may under the Act be authorized by a designated independent senior officer working for the judicial Commissioner. In addition, since the 1950s there has been a standing instruction from the Foreign Secretary to the UK agencies that any operation that is contemplated, whether domestic or foreign, that could have an impact on foreign policy must be cleared by the Secretary of State or a senior official in the Foreign Office. Such a system ensures that there is an audit trail of who agreed to what. Public confidence issues quickly arise if that is not the case, as was exposed during inquiries into British Army covert intelligence gathering in the Northern Ireland conflict in the period of the 1970s and 1980s before legislation was introduced. ${ }^{9}$

A different application of this key concept comes in the regulation of the use in intelligence and security activity of AI algorithms to categorize data. If such a machine learning system makes a wrong determination about an individual which results in an injustice, such as placing the innocent person on a no-fly list or providing targeting data for a direct intervention, who is to be held accountable - the coder who wrote the algorithm, the senior responsible owner of the decision system in which it was embedded, the senior line manager or minister who authorized the policy for its use for that purpose? With the most advanced AI algorithms it may be hard to establish an audit trail of how the selection system arrived at its result in any particular case. An evolutionary machine learning process can result in the machine being able to select desired characteristics from bulk data without conscious programming of decision rules. There is a heavy ethical responsibility on the technologists designing machine learning systems to ensure that the users 
can fully understand the implications of using such systems. The ethics of managing AI accountability in such circumstances (such as driverless vehicle accidents) is an issue going way beyond the realms of security and intelligence activity. However, at present there is no satisfactory ethical code for AI applications that is internationally accepted.

\section{A reasonable prospect of success in achieving the desired ends from the activity}

Originally, as part of the Just War tradition, this was an injunction against operations such as vainglorious cavalry charges that needlessly expose the forces involved to extreme danger. In the intelligence context this principle can be said to rule out activity where there is no justification for taking significant ethical risk, for example in "fishing expeditions" that involve engaging the privacy rights of many innocent people with no clear idea in mind as to what is being sought. When intelligence agencies access data in bulk, by definition the majority of individuals contained within the data set are not, and are unlikely to become, of interest to the Security and Intelligence Agencies in the exercise of their statutory functions (Home Office 2016). It is the problem of the haystack and the needle. There needs therefore to be a reasonable belief, on the basis of past experience or specific research, that there can be an expectation of sufficient effectiveness to justify the level of risk being run by the operation. For example, in the case of bulk access to communications data, the application of some filtering or other targeting or selection mechanism has an acceptable likelihood of pulling out for the analyst material that is relevant to an authorized intelligence requirement. Applying this principle rules out "mass surveillance", or keeping the communications of a large group of citizens under observation in the blind hope that something may turn up to justify the operation.

The effective application of an AI selector also depends on having the algorithm correctly exposed to data that is representative of the real situation. Ethically unacceptable cultural, racial or gender bias in selection decisions can result if the training data is narrowly compiled and does not reflect what will be found in practice. Such biases can be hard to spot (Ledford 2019).

\section{Discrimination}

Discrimination is needed to manage collateral harm, in the basic sense of the ability to see the difference between classes of things or people. In the laws of war that emerged from the Just War tradition the military commander faces, on the one hand, legitimate military targets and on the other hand groups of people that require protection such as innocent civilians not participating on the side of the adversary or surrendering soldiers. Before a new type of weapon is introduced into the battlefield there needs to be a legal assessment that the combination of weapon and operator is capable of discriminating between them. By analogy, when a new digital intelligence gathering method is introduced there needs to be 
confidence that there will be the human and technical ability to assess and manage the risk of collateral harm, including the implications of privacy intrusion into the lives of those not intended to be the target of intelligence gathering.

Collateral intrusion has always been an issue with interception of fixed line telephones that capture the communications of all users in a home not just the targeted suspect. Bulk access operations have to be operated under clear ethical constraints to take account of the evident fact that almost all bulk data relates to those who are not and would never be the legitimate target of intelligence activity. Agencies must recognize that their privacy rights are engaged, right from the outset of planning such bulk operations, but with careful design of algorithms and procedures for destroying unexamined material after a set period that ethical risk can be managed down to an acceptable level applying the necessity and proportionality tests.

This principle also provides the basis for ethical oversight of the artificial intelligence algorithms that are increasingly being used to question large data sets. In any practical decision system (whether conducted by humans, by humans assisted by machine intelligence or by AI algorithms themselves) what is a reasonable prospect of success has to be defined, given that the possibility of error cannot be excluded. AI applications that have a low rate of false positives are said to have high specificity. Those with a low rate of false negatives have high sensitivity. Where the cursor is set between these will depend upon the consequences of getting it wrong either way. A no-fly security system can be expected to allow more false positives (preventing an innocent passenger from flying) in return for fewer false negatives (allowing a genuine terrorist suspect to board an aircraft). Key to achieving an acceptable balance of results is understanding what the true level of the decision factor is likely to be. For example, an antibody test for corona virus might have a $95 \%$ level of both specificity and sensitivity but despite these high levels, applied to a community of 500 people with a $5 \%$ infection rate an individual who tests positive only has a $50 \%$ chance of genuinely having the antibodies (Frasier 2020).

\section{Necessity}

Necessity is the final Just War-derived concept that can be used to judge the ethical adequacy of an operation. Is it really necessary to do this? Additional Protocol 1 to the 1949 Geneva Conventions applicable to armed conflict places a requirement on a military commander to be able to justify that an operation is a necessary part of achieving his military aim. There needs to be confidence that there is no reasonable alternative way to achieve the ends of the authorized mission at lesser ethical risk. That applies to intelligence activity, for example establishing that wanted information cannot be obtained more easily from open sources, or indeed already exists somewhere in the intelligence community. There are many databases of personal data relating to individuals that can be accessed with appropriate legal authority. Government examples include criminal records, passports and social security records, driving and vehicle licences, voting and 
information gathered at the border. Private sector information includes airline bookings (and advanced passenger information shared between nations), credit card and financial data, on-line purchases and internet connection records and mobile telephone usage data. With the right legal authority under data protection legislation, however, such personal data can be accessed (under the European Convention on Human Rights/Human Rights Act 1999) for the purposes of national security, the detection and prevention of serious crime and for the protection of health.

These ethical concepts, especially necessity and proportionality, form a useful framework for jus in intelligentia in today's digital world. On the other hand, the jus ad intelligentiam to help judge the acceptability of digital intelligence capability itself is harder to pin down. We have to accept the primacy today of the nation-state in relation to the security of the citizen (e.g. as set out in article 4(2) of the Treaty of European Union) and nation-states will choose to maintain the means to defend themselves against digital threats and to be able to exploit to that end the digitized personal data that unavoidably is part of modern life. To that end intelligence activity is the first not the last resort. But the ethical injunction of necessity remains.

\section{The ethics of being a cyber power: offensive cyber capabilities and deterrence in cyberspace}

There is nevertheless considerable interest in international legal and diplomatic circles in the development of norms for responsible conduct in cyberspace that might if followed by the democracies eventually become part of accepted international law. Some norms, for example, might take the Geneva Convention's route and identify classes of potential targets to be protected, such as not targeting the core structures of the internet and not deliberately weakening the encryption on which key applications depend, including for financial systems and key protocols such as Secure Sockets Layer (SSL). International Human Rights Law is already considered by many states to apply in cyberspace (as per the Tallinn Manual drawn up by North Atlantic Treaty Organization experts) (Schmitt 2017). Domestic legal regulation and oversight measures can help the search for norms as examples of confidence building measures both for the domestic population and for international confidence in rules-based international order.

Espionage, including digital espionage, is however not regulated by international law, being regarded as "fair game" between nations, with the onus being on a nation to defend itself. Some espionage techniques could nevertheless open weaknesses in the "commons" of the internet and the difference between a digital espionage operation and a cyberattack could be only a few lines of code. Such considerations, along with the impossibility of adequate verification, seem to rule out an arms control approach to limiting hostile activity in cyberspace or to applying the approach of the Hague conventions on weaponry (such as restrictions on landmines) to prohibiting techniques that carry high risk of wider harm (such as seen in the spread of the Wannacry and NotPetya attacks). 
Hence, developing norms for state behaviour in cyberspace is as challenging a prospect as it is an important task. However, there have been important recent interventions that represent significant early steps in what is likely to be a long, non-linear, endeavour.

On the basis of these, we can say that one essential foundation on which international norms must be built is robust and transparent national legislation regulating intrusive intelligence practice in the digital sphere. Another is the open and regular discussion of principles that should govern intelligence and security behaviour. There is clear potential for the second of these to act as a confidence-building measure by building on the foundation provided by the first; intelligence managers in liberal democratic states can act as norm entrepreneurs ${ }^{10}$ in this field but in doing so they are not operating in a vacuum but in a context underpinned by openly debated and clearly understood national legal frameworks. These give the interventions by intelligence managers much of their force as confidence-building measures. ${ }^{11}$

A very good example of this process of norm development can be seen in the Fullerton Lecture given by GCHQ Director Jeremy Fleming in Singapore in February 2019, which was widely reported and made easily accessible in both text and video forms (Fleming 2019). ${ }^{12}$ This addressed core issues related to being a Cyber Power: "What does it mean? What does a country need to have at its disposal to be a Cyber Power? How should it exercise that power? What rules, regulations and ethics are needed to exercise power responsibly?" (Fleming 2019). His answer was that a cyber power had the following three characteristics:

One, it has to be world class in safeguarding the cyber health of its citizens, businesses and institutions - it must protect the digital homeland.

Two, it has to have the legal, ethical and regulatory regimes to foster public trust - without which we do not have a licence to operate in cyber space.

And three, when the security of its citizens are threatened it has to have the ability - in extremis and in accordance with international law - to project cyber power to disrupt, deny or degrade.

(Fleming 2019)

Ethics and legality were not treated as synonymous, but as complementary requirements to be met that, together, could give confidence that cyber power was being used responsibly:

I've always liked the philosopher and scientist Aldo Leopold's definition of ethics. He said it was about "doing the right thing even when no one else is watching". Nowhere does that apply so much than in the world of national security. In spying, intelligence gathering, espionage - whatever term you'd like to use - I believe that there are ethical rules and boundaries, and these should always be followed and upheld.

Of course, the UK is a liberal democracy. There is extensive oversight of the work of the intelligence and security agencies. Someone else, typically a senior judge, is always watching over what we do. 
It's perhaps easy to be ethical in such a situation - and in our democracies, sometimes we take that oversight for granted. Nonetheless, our analysts are constantly reminded that it is not enough to be able to do something ... it is not even enough for it to be legal to do something ... it must also be right to do something.

(Fleming 2019)

Here, then, the foundation of confidence lies in robust national legislation and oversight mechanisms onto which the emphasis on professional ethics in training and professional development added further assurance. One objection to this line of reasoning could be that these are simply words, that talk is cheap. But the words used are significant. The second characteristic of a cyber power identified by Fleming (earlier) was that the "legal, ethical and regulatory regimes" were in place that could "foster public trust". Without these, "we do not have a licence to operate in cyber space". Later in the speech, Fleming returned to this idea of "our licence to operate" which "enables us to retain the trust of the societies we serve". Both of these terms reflected the titles of reports advocating significant reform of the regulatory regimes governing digital intelligence collection and interference in the wake of legal challenges following the Snowden disclosures and part of an extended period in the UK of public discussion of intelligence collection practices. The idea of a "licence to operate" comes from the title of a report from the Independent Surveillance Review, A Democratic Licence to Operate, published in July 2015, on which one of us (David Omand) served as a panel member (Independent Surveillance Review 2015). The reference to the importance of retaining trust recalls the title of the June 2015 report by David Anderson, QC, the Independent Reviewer of Terrorism Legislation, A Question of Trust (Anderson 2014). Both of these influenced the nature of the 2016 Investigatory Powers Act, the post-Snowden regulatory framework passed (by a large cross-party majority) for digital intelligence collection and use, one feature of which was enhanced oversight.

This act created a powerful Commissioner (a very senior judge), a new system of warrants for access to bulk data and an independent body to authorize law enforcement access to communications data and internet data connection records (the who called whom, when, where and how). It is this oversight capability that adds to confidence in interventions such as this by Jeremy Fleming. For example, the 2016 Investigatory Powers Act provided for the need for prior approval by Judicial Commissioners of warrants for the use of intrusive powers such as interception, equipment interference and the use of surveillance in sensitive environments. It also created the Investigatory Powers Commissioner's Office (IPCO) to consist of around 70 staff comprising 15 Judicial Commissioners (current and recently retired High Court, Court of Appeal and Supreme Court Judges), a Technical Advisory Panel of scientific experts and around 50 official staff, including lawyers and communications experts.

In its 2017 Annual Report, IPCO set out a particular interest in Section 7 Authorizations - those under Section 7 of the Intelligence Services Act 1994, 
referring to activity that SIS and GCHQ carry out outside the British Islands where the authorization removes any liability under UK criminal or civil law for what is done. In the course of overseeing these, Sir John Goldring, the deputy IPC,

"conducted two inspections of GCHQ and SIS, in the spring and autumn of 2017, along with two of SIS's overseas stations in early 2017 [and] separate inspections of the FCO as regards its work with SIS and GCHQ during the summer of 2017", focusing on "the authorisation and review processes, and particularly whether the Foreign Secretary was provided with a proper understanding of the activity that would be sanctioned by the authorisation".

(Investigatory Powers Commission 2019, para. 11.1-11.15)

Both of IPCO's annual reports to date are detailed (131 and 141 pages-long respectively), publicly available, are clear about inspection methodology and set out errors and breaches in relation to warranting. In short, the oversight mechanism provides a firm basis for intelligence managers to build in discussing ethical approaches to cyber power and act as norm entrepreneurs.

Given all of this, when is it right for a cyber power to deploy its offensive cyber capability, "taking action online that has direct real-world effect" in Jeremy Fleming's words? Here again we can see the utility of drawing on and adapting Just War precepts to guide our thinking. This is one area where we can clearly see the relevance of thinking in terms of an intelligence equivalent of jus ad bellum. Underpinning these considerations is the principle that there are boundaries of acceptable state behaviour in cyberspace (Fleming 2019) and that a core characteristic of the responsible cyber power is the way in which it uses that power in a manner that encourages other states to operate within these boundaries and in support of the rules-based international order. This contributes to the development of norms in this still rapidly developing sphere of activity. Where states seek to act outside these boundaries, the responsible cyber power can act to deter by attaching costs, both reputational and/or physical. In this sense, then, applying the notion of deterrence here means influencing others not to act in ways that harm us. There are a number of forms this approach can take, for example:

- working with other nations to expose adversary actions and intentions to criticism

- influencing via diplomacy and nudging, including with sanctions

- offering inducements, such as of a reset in relations with the option to withhold if unacceptable behaviour continues

- emphasizing mutual economic inter-dependence, deterrence by entanglement with the potential adversary, as Joseph Nye has called it (Nye 2017) ${ }^{13}$

- making ourselves a harder target and thus making life as difficult as we can for the attackers, exercising deterrence by denial of benefit to the aggressor, or at least affecting the cost-benefit calculations of the aggressor 
- threatening consequences, including via the use of armed force or offensive cyber means, which provide the essence of deterrence by punishment

We could arrange these as a scale of $\mathrm{D}$ : from $\mathrm{D}$ minor, detection and exposure to disapproval, to discouragement, to deflection, to dissuasion and finally to D major, the formal structures of defence and deterrence found in NATO strategy. Digital intelligence aimed at understanding the capabilities and intentions of potential adversaries is at the heart of decisions about how best to deter potential threats, including through the development of offensive cyber capabilities, at three levels.

First, for armed forces, ours and those of potential adversaries, the digital is now a domain of warfare. Any future armed conflict is likely to involve the use of cyber weapons, just as in the recent past armed forces used electronic warfare. As noted earlier the use of any weapon system needs to be constrained by jus in bello ethical considerations, for example adherence to international humanitarian law and the Geneva Conventions. The development of such weapons inevitably involves significant prior intelligence gathering on the digital networks or capabilities that are the target of the system.

Second, many states are acquiring the capability to inflict highly damaging cyberattacks on national infrastructure, potentially causing death and damage that would be equivalent to a kinetic armed attack. For the UK and NATO allies it is important that potential adversaries understand that such "Article 5 level" attacks would engage the full weight of NATO's defence and deterrence strategy. The Obama Administration warned in 2011 that it would

respond to hostile acts in cyberspace as we would to any other threat to our country. We reserve the right to use all necessary means - diplomatic, informational, military, and economic - as appropriate and consistent with applicable international law, in order to defend our Nation, our allies, our partners, and our interests.

(BBC News 2011)

Aggressors must understand that the response to such attacks need not be confined to cyberspace.

But then we have the third level of everyday cyber threat, well below the threshold of armed attack, ranging from fraud to digital subversion of democracy, as seen during the 2016 US Presidential election campaign and described earlier. The acronym CESSPIT encapsulates this as: Crime, Espionage, Sabotage and Subversion perverting internet technology.

The CESSPIT activities below the threshold of armed attack are best managed as a whole of nation effort to reduce the risk to the citizen, including education of business and citizens to operate safely in the digital world. Active cyber defences can seek out and block malware, bad addresses and dodgy websites. Children can be taught critical thinking so that they are better equipped to detect deception, exaggeration and falsehood on-line. 
We need to make life as difficult as possible for the attackers by penetrating and disrupting their networks to create difficulty and make attacks more costly in terms of effort. Such persistent engagement is a contribution to deterrence by denial. It could be described as forward active dissuasion (FAD), like having police officers on the streets. That contributes to reducing the risk but, like the threat of arrest for criminals, it will not stop them from trying to commit crime.

\section{Conclusions}

Intelligence officers are in ethical terms natural consequentialists, wishing to have the acceptability of their methods judged by their results, for example in terms of terrorist plots uncovered and frustrated. This principle underlies the requirement in the UK's 2016 Investigatory Powers Act for proportionality. There has to be a relationship between the ethical risks being run and the harms it is sought to prevent. The principle of necessity is also incorporated into the 2016 Act, that digital operations that involve an ethical risk (which the Act defines) need adequate justification. There is a moral obligation to consider whether the results might be obtained by a method (such as use of open sources) that carries lower ethical risk.

Some democratic societies, including the UK, have insisted on importing a deontological element into the consequentialist ethical approach of their agencies by constraining them to act in accordance with universal human rights, as laid down in the Council of Europe Convention on Human Rights and translated into UK domestic law by the 1999 Human Rights Act. That includes the absolute prohibition on obtaining information by torture and other unlawful interrogation methods. In relation to digital intelligence operations it also requires that balances be sought within the basket of human rights, especially over respecting privacy rights of citizens as well as their right to life and the enjoyment of property, and the protection of freedom of speech. There is also an aretaic, value ethics, element to the recruitment and training of intelligence officers to help them know the settings of their internal moral compasses. Taken together, drawing on these consequentialist, deontological and aretaic traditions, the UK intelligence and security agencies should be better able to demonstrate that their digital activity conforms to domestic law that itself is based on ethical principles that have commanded a significant cross-party majority in Parliament. As technologies continue to be developed, and exploited for intelligence purpose, that "licence to operate" will need to be revalidated and renewed.

The use of AI algorithms to identify individuals of interest and patterns of covert communication is now becoming commonplace. The ethical principle that must be met is that the computer algorithms being used are sufficiently discriminating so as to give an acceptable likelihood of picking out the sought-for communication and a lower risk of selecting irrelevant material. To achieve that there needs to be careful attention to prevent unconscious biases, for example where the data used to train the algorithms does not reflect the actual population of data to which the algorithms will be applied. The agency must therefore be confident that 
filtering and selection processes are sufficiently discriminating so as to minimize the extent of invasion of privacy of the innocent. ${ }^{14}$

Being pro-active in defending the digital space brings with it legal and ethical issues. Advanced digital intelligence tools will be needed for defensive purposes. As with conventional weaponry, the same tools will be available to the authorities of the autocracies. What matters therefore is to have a system in the democracies of legal authorization, oversight and ethical regulation of the purpose for which the technology is to be applied. It is this sense of moral purpose, underpinned by the principle of restraint, that distinguishes the regulated activity of the intelligence agencies of liberal democracies from those of the autocracies.

Recent UK experience is that with greater transparency over the necessity for secret intelligence to prevent harms to the public and an evidence-based vigorous Parliamentary and public debate it is possible to arrive at a democratic consensus over how intelligence activity should be regulated under the law (Independent Surveillance Review 2015). The debate has enhanced public trust in the security and intelligence authorities, whilst the secret agencies and their law enforcement partners have been able to use these powers effectively. The UK Investigative Powers Act 2016 marked a new deal between the British intelligence communities in which a legal "licence to operate" is given for intrusive intelligence methods in return for enhanced ethical safeguards and oversight. Even since 2016, however, digital technology has continued to develop whilst the public has become much more sensitive to the use (and misuse) of their personal data. The long tradition of Just War thinking has provided a set of concepts such as right authority, proportionality and necessity that can be used to help manage the additional ethical risks that come with the application of digital technology and machine learning to the worlds of national intelligence, security and public safety. Offensive cyber capabilities expand the realm in which ethical guidelines need to be applied.

Here, we see again the " 3 Rs" framework that defines liberal intelligence in operation: the rule of law; regulation and restraint (Omand and Phythian 2018, 225-39). The transparent rule of law which provides for robust regulation, evidence of which is made publicly available, forms the basis on which intelligence managers can act as norm entrepreneurs, shaping developments by emphasizing the expectations that surround the exercise of responsible cyber power and setting out principles around this that will guide their state's and organization's behaviour. These interventions also set out the costs that are likely to attach to unacceptable conduct in the digital sphere. Notwithstanding the clear exposition of the offensive potential inherent within the notion of a cyber power, and key to its deployment as a deterrent, this is an approach characterized by restraint.

\section{Notes}

1 This represents a revival of the term coined by the Argentinean philosopher of science Mario Bunge in the 1970s (Bunge 1977).

2 Bunge wrote of the Technologist being "Torn Between Conflicting Interests" and set out a scenario where: 
"M: The management expects an efficient and profitable plant.

$\mathrm{W}$ : The workers expect satisfactory working conditions.

$\mathrm{N}$ : The neighbors expect a pollution-free operation.

$\mathrm{T}$ : The professional colleagues expect a technologically advanced design, execution and operation of the project.

C: The consumers expect useful and reasonably priced goods".

(Bunge 1977)

The possible parallels with the conflicting expectations that can attach to intelligence are obvious.

3 For example Marrin and Clemente (2005) and Marrin and Torres (2017).

4 On the health security dimension specifically, see Lentzos, Goodman, and Wilson (2020) and the other articles in that special issue on Health Security Intelligence.

5 See also Rankin (2020).

6 For example, Naughton (2020b) and Urwin and Wheeler (2020). For another perspective, see Foges (2020).

7 See also Allen (2020).

8 See also Omand and Phythian $(2018,79-83)$.

9 For example, the inquiries by Chief Constable John Stevens and by the Canadian Judge Peter Cory examined allegations of collusion between the British Army and Loyalist paramilitary groups, subsequently investigated in detail by Sir Desmond de Silva, who concluded in his inquiry published in 2012 that there was an absence of clear structures and guidelines to ensure accountability for the use and dissemination of intelligence and to ensure intelligence is not exploited illegally, had been (de Silva 2012).

10 The term comes from Sunstein (1996).

11 On norms and confidence-building measures in cyberspace (Broeders, Boeke, and Georgieva 2019).

12 A further good example is provided by Alex Younger's December 2018 speech at St. Andrews University.

13 See also Mandel (2017).

14 The most detailed description of how this operates can be found in the Academy of Sciences report, Bulk Collection of Signals Intelligence (Board, Sciences, and Council 2015).

\section{References}

Ackerman, Spencer, and James Ball. 2014. "Optic Nerve: Millions of Yahoo Webcam Images Intercepted by GCHQ". The Guardian, February 28. www.theguardian.com/ world/2014/feb/27/gchq-nsa-webcam-images-internet-yahoo.

Allen, Danielle. 2020. "America Needs to Be on a War Footing”. Washington Post, March 20. www.washingtonpost.com/opinions/2020/03/20/america-needs-be-war-footing/.

Allen, Danielle, Lucas Stanczyk, I. Glenn Cohen, Carmel Shachar, Rajiv Sethi, Glen Weyl, and Rosa Brooks. 2020. Securing Justice, Health, and Democracy against the COVID19 Threat. Cambridge, MA: Edmond J. Safra Center for Ethics, Harvard University.

Anderson, David. 2014. A Question of Trust: Report of the Investigatory Powers Review. London: HMSO. www.gov.uk/government/publications/a-question-of-trust-report-ofthe-investigatory-powers-review.

BBC News. 2011. "US Pentagon to Treat Cyber-Attacks as 'Acts of War'”. BBC News, June 1. www.bbc.com/news/world-us-canada-13614125.

Board, Computer Science and Telecommunications, Division on Engineering and Physical Sciences, and National Research Council. 2015. Bulk Collection of Signals Intelligence: Technical Options. Washington: National Academies Press. 
Broeders, Dennis, Sergei Boeke, and Ilina Georgieva. 2019. Foreign Intelligence in the Digital Age Navigating a State of 'Unpeace'. The Hague: The Hague Program for Cyber Norms. www.thehaguecybernorms.nl/news-and-events-posts/policy-brief-foreignintelligence-in-the-digital-age-navigating-a-state-of-unpeace.

Bunge, Mario. 1977. “Towards a Technoethics”. The Monist 60 (1): 96-107.

European Commission. 2020. "Coronavirus: EU Strengthens Action to Tackle Disinformation”. European Commission. June 10. https://ec.europa.eu/commission/presscorner/ detail/en/IP_20_1006.

Fleming, Jeremy. 2019. "Director's Speech on Cyber Power: As Delivered". March 29. www.gchq.gov.uk/speech/jeremy-fleming-fullerton-speech-singapore-2019.

Foges, Clare. 2020. "We Need Big Brother to Beat This Virus". The Times, April 20. www. thetimes.co.uk/article/we-need-big-brother-to-beat-this-virus-5b0nj168r.

Frasier, Sarah Lewin. 2020. "False Positive Alarm". Scientific American, 20 July 2020.

Hart, Vi, Divya Siddarth, Bethan Cantrell, Lila Tretikov, Peter Eckersley, John Langford, Scott Leibrand, et al. 2020. Outpacing the Virus: Digital Response to Containing the Spread of COVID-19 While Mitigating Privacy Risks: COVID-19 Rapid Response Impact Initiative: White Paper 5. Cambridge, MA: Edmond J. Safra Center for Ethics, Harvard University. https://ethics.harvard.edu/outpacing-virus.

Home Office. 2018. "Security and Intelligence Agencies Retention and Use of Bulk Personal Databases. Code of Practice". https://assets.publishing.service.gov.uk/government/ uploads/system/uploads/attachment_data/file/715477/Bulk_Communications_Data_ Code_of_Practice.pdf.

Independent Surveillance Review. 2015. A Democratic Licence to Operate. London: RUSI. https://rusi.org/sites/default/files/20150714_whr_2-15_a_democratic_licence_ to_operate.pdf.

Investigatory Powers Commission. 2019. Annual Report 2017 HC 1780. London: HMSO. www.ipco.org.uk/docs/IPCO\%20Annual\%20Report\%202017\%20Web\%20Accessible\% 20Version\%2020190131.pdf.

Jankowicz, Nina, and Cindy Otis. 2020. "Facebook Groups Are Destroying America". Wired, June 17. www.wired.com/story/facebook-groups-are-destroying-america/.

Ledford, Heidi. 2019. "Millions of Black People Affected by Racial Bias in HealthCare Algorithms". Nature 574 (7780): 608-9. https://doi.org/10.1038/d41586-01903228-6.

Lentzos, Filippa, Michael S. Goodman, and James M. Wilson. 2020. "Health Security Intelligence: Engaging across Disciplines and Sectors". Intelligence and National Security 35 (4): 465-76. https://doi.org/10.1080/02684527.2020.1750166.

Mandel, Robert. 2017. Optimizing Cyberdeterrence: A Comprehensive Strategy for Preventing Foreign Cyberattacks. Illustrated edition. Washington, DC: Georgetown University Press.

Marrin, Stephen, and Efren Torres. 2017. "Improving How to Think in Intelligence Analysis and Medicine". Intelligence and National Security 32 (5): 649-62. https://doi.org/ 10.1080/02684527.2017.1311472.

Marrin, Stephen, and Jonathan D. Clemente. 2005. "Improving Intelligence Analysis by Looking to the Medical Profession". International Journal of Intelligence and CounterIntelligence 18 (4): 707-29. https://doi.org/10.1080/08850600590945434.

McNeill, William H. 1983. The Pursuit of Power: Technology, Armed Force, and Society since A.D. 1000. Oxford: Basil Blackwell.

Mill, John Stuart. 1869. On Liberty. London: Longmans, Green, Reader and Dyer. 
Naughton, John. 2020a. "When Covid-19 Has Done with Us, What Will Be the New Normal?" The Guardian, April 18. www.theguardian.com/commentisfree/2020/apr/18/ when-covid-19-has-done-with-us-what-will-be-the-new-normal.

- 2020b. "Contact Apps Won't End Lockdown: But They Might Kill off Democracy". The Guardian, April 25. www.theguardian.com/commentisfree/2020/apr/25/ contact-apps-wont-end-lockdown-but-they-might-kill-off-democracy.

Norton-Taylor,Richard.2015. "Britain's SpyAgencies:TheOnly WatchdogIstheWorkforce". The Guardian, March 12. www.theguardian.com/news/defence-and-security-blog/2015/ mar/12/britains-spy-agencies-the-only-watchdog-is-the-workforce.

Nye, Joseph. 2017. "Deterrence and Dissuasion in Cyberspace". International Security 41 (3): 44-71. https://doi.org/10.1162/ISEC_a_00266.

Omand, David. 2010. Securing the State. London: Hurst.

Omand, David. 2020. How Spies Think: Ten Lessons in Intelligence. New York: Viking.

Omand, David, and Mark Phythian. 2018. Principled Spying: The Ethics of Secret Intelligence. Washington, DC: Georgetown University Press.

Philp, Catherine. 2020. "State-Sponsored Hackers 'Trying to Steal Coronavirus Vaccine Secrets"”. The Times, May 5. www.thetimes.co.uk/article/state-sponsored-hackers-tryingto-steal-coronavirus-vaccine-secrets-mrmrlzcst.

Rankin, Jennifer. 2020. “China Joins Kremlin on EU's List of Active Disinformation Threats". The Guardian, June 11.

Schmitt, Michael N., ed. 2017. Tallinn Manual 2.0 on the International Law Applicable to Cyber Operations. Cambridge: Cambridge University Press. https://doi. org/10.1017/9781316822524.

Silva, Desmond de. 2012. The Report of the Patrick Finucane Review. London: House of Commons. https://assets.publishing.service.gov.uk/government/uploads/system/uploads/ attachment_data/file/246867/0802.pdf.

Sunstein, Cass R. 1996. "Social Norms and Social Roles". Columbia Law Review 96: 903-68.

The Economist. 2020. "Creating the Coronopticon". May 28.

Urwin, Rosamund, and Carolline Wheeler. 2020. "Coronavirus Tracker App Could Put Britons under Permanent Surveillance, Warn Tory Rebels". The Sunday Times, May 10. www.thetimes.co.uk/article/coronavirus-tracker-app-could-put-britons-underpermanent-surveillance-warn-tory-rebels-5v0w9p5ns.

Warner, Michael. 2014. The Rise and Fall of Intelligence: An International Security History. Washington, DC: Georgetown University Press.

Younger, Alex. 2018. "MI6 'C' Speech on Fourth Generation Espionage”. Gov.Uk. December 3. www.gov.uk/government/speeches/mi6-c-speech-on-fourth-generation-espionage.

Zuboff, Shoshana. 2019. The Age of Surveillance Capitalism: The Fight for a Human Future at the New Frontier of Power. London: Profile Books. 